\title{
Undernutrition and associated factors of among older adults in Ethiopia: Systematic review and meta-analysis
}

Hiwot Yisak ( $\square$ hyisak@yahoo.com )

https://orcid.org/0000-0003-2922-289X

\section{Systematic Review}

Keywords: undernutrition, older adults, Ethiopia, systematic review and meta-analysis

Posted Date: January 21st, 2022

DOl: https://doi.org/10.21203/rs.3.rs-1278141/v1

License: (1) (1) This work is licensed under a Creative Commons Attribution 4.0 International License. Read Full License 


\section{Abstract}

Introduction: In older adults, undernutrition is a common and dangerous condition. Undernutrition contributes significantly to morbidity and mortality in older adults today, without a doubt. Undernutrition and accidental weight loss contribute to health decline, decreased physical and cognitive functional status, higher healthcare consumption, premature institutionalization, and increased mortality. Undernutrition in older adults may be reduced if the overall prevalence and determinant factors were addressed. So, the goal of this study was to determine the pooled prevalence and factors associated with undernutrition among the older adults in Ethiopia.

Method: The protocol in this study was registered in the International Prospective Register of Systematic Reviews (PROSPERO) database and can be accessed with the protocol number CRD42021254805.A selection of publications, data extraction, and reported results for the review was designed according to the preferred reporting items for systematic reviews and meta-analysis (PRISMA) guidelines. The quality of individual studies included in this meta-analysis was assessed using the STROBE (Strengthening the Reporting of Observational Studies in Epidemiology) checklist. A total of 8 independent studies were eligible and enrolled for final analysis. The heterogeneity among studies used for this meta-analysis was assessed using the $I^{2}$ test. Thus, a fixed-effect model at $95 \%$ $\mathrm{Cl}$ was used for estimating the overall effect. The meta-analysis was conducted using Stata software (version 14, STATA Corp College Station, TX), where $\mathrm{p}<$ 0.05 was considered statistically significant.

Results: In the estimation of the pooled prevalence of undernutrition, a total of 4,628 older adults from eight studies were included. the pooled prevalence of undernutrition among older adults in Ethiopia was 20.53\% (95\% Cl: $17.39 \%, 23.67 \%)$. The study revealed that males had higher odds of being undernutrition as compared to females with AOR 5.88 (95\% Cl: 5.00,6.66). Older adults in the age range of 65-74 (young-old) were less likely to be undernourished as compared to those whose age was above 85 (old-old) with AOR $022(95 \% \mathrm{Cl}: 0.22,0.25)$. Older adults who were depressed had higher odds of undernutrition as compared to their counterparts with AOR 1.27 (95\% Cl:1.19, 1.37). On the other hand, older adults from households with poor wealth index were two (AOR=1.90; $95 \% \mathrm{Cl}$ : 1.08, 3.32) times more likely to be undernourished as compared to those who were from rich households.

Conclusion: The burden of undernutrition in Ethiopia is still significant, according to this report. As a result, different intervention measures to minimize the prevalence of undernutrition among Ethiopia's older adults are urgently needed

\section{Introduction}

According to a factsheet released by the World Health Organization (WHO), around 12\% of the global population (900 million people) was aged 60 years or over in 2015 , with forecasts that this number will nearly double to $22 \%$ (2 billion people) by 2050 (1).

Chronic diseases and disability are becoming a public health challenge as the world's population ages, particularly in developing nations where the healthcare system is underdeveloped and resources are scarce(2). Furthermore, the older adults population in developing countries is expanding at a faster rate than in developed countries (3). This rapid demographic shift leaves these countries with insufficient time to construct their health, economic, and social infrastructures to deal with the aging population. Another issue is that in developing countries, population aging is accompanied by persistent poverty (4).

Healthy diets and exercise are frequently emphasized in nutrition to reduce the chance of acquiring lifestyle diseases such as cancer, diabetes, and cardiovascular disease. However, as people get older, their nutritional objectives shift to fulfilling greater nutrient needs while consuming less energy and preventing lean muscle loss $(5,6)$.

In older adults, undernutrition is a common and dangerous condition. Undernutrition contributes significantly to morbidity and mortality in older adults today, without a doubt (7).

The number of existing geriatric disorders had a positive association with the probability of undernutrition. Poor nutritional status was linked to depression, dementia, functional dependency, and various co-morbidities. (8). Undernutrition and poor nutritional status in the older population are major concerns. Undernutrition and accidental weight loss contribute to health decline, decreased physical and cognitive functional status, higher healthcare consumption, premature institutionalization, and increased mortality (9).

Weight loss in older persons is frequently accompanied by a decrease in muscle mass, which can harm functional status. The advancement to undernutrition is mostly treacherous and often unnoticed. Undernutrition in older people is linked to problems and early death (10). On the other side, they are overweight and obese due to a lack of mobility and a sedentary lifestyle (11).

During the coronavirus (COVID -19) pandemic, investigations have shown that older COVID-19 patients are most at risk of undernutrition or co-undernutrition. COVID-19 can also impact the mucosal epithelium and induce gastrointestinal problems, which can wreak havoc on the nutritional status of older COVID-19 patients(12).

Undernutrition in older adults may be reduced if the overall prevalence and determinant factors were addressed. So, the goal of this study is to see the prevalence and determinants of undernutrition among older adults in Ethiopia.

\section{Materials And Methods}

\section{Study protocol registration}

The protocol in this study was registered in the International Prospective Register of Systematic Reviews (PROSPERO) database and can be accessed with a protocol number CRD42021254805 


\section{Search strategy}

We made an inclusive literature search conducted from October 2021 to November 2021 from PubMed, Medline, and Google Scholar; in parallel using search strings adapted to the requirements of each database. A selection of publications, data extraction, and reported results for the review was designed according to the preferred reporting items for systematic reviews and meta-analysis (PRISMA) guidelines. Throughout the comprehensive literature search, the following search terms were used: "Undernutrition OR Nutritional Deficiency OR Undernutrition OR malnourishment OR undernourishment OR cachexia OR Low BMI OR nutritional status OR starvation AND Aged OR Older adults OR older adults OR geriatrics OR advanced years AND Ethiopia". Furthermore, we checked the reference lists of published studies to identify additional articles. The identification and selection of the papers in all the researched databases were made independently by three researchers (HY, MA, and AT.), respecting the eligibility criteria and without the use of filters. Then, the duplications between the databases were eliminated. Next, a refinement was performed to select studies regarding the theme addressed, by reading the titles and abstracts. In the event of disagreement between the investigators, the study was re-evaluated and the doubts obtained in the process of applying the eligibility criteria were discussed until a consensus was reached among the members.

\section{Eligibility criteria}

The eligibility criteria used were: articles that presented original data on prevalence and determinants of undernutrition among g the older adults in Ethiopia. The study was restricted to those articles whose year of publication was from 2010-2021. The selected language of publication was English. We excluded studies that used secondary data, reviews review of reviews, and those studies which did not report the outcome of interest.

\section{Evaluation of study quality}

The STROBE (Strengthening the Reporting of Observational Studies in Epidemiology) checklist was used to assess the quality of the individual studies included in this meta-analysis. Internal validity (measurement skewed) and external validity (selection biased) of papers included in this meta-analysis are assessed using the checklist. We chose eight quality assessment factors from the 22 STROBE items: sample size, sampling methods, response rate, statistical analysis, ethical consideration, outcome measure, confounding, and research limitation from the 22 STROBE items. Studies were given a score of 1 (if the criterion was met) or 0 (if the criterion was not met). The overall quality score was calculated by adding the assigned numbers for each parameter and classified as low (<3), medium (4 - 6), or high ( $>7)(13)$.

\section{Summary of the quality assessment parameters (Table 1)}

- Low quality (<3 quality score) $=0$

- Medium quality (4-6 quality score) $=2(25 \%)$

- High quality (>7 quality score) $=6(75 \%)$

\section{Selection and identification of studies}

All studies identified through different databases were combined, exported, and managed using COVIDENCE software. All duplicated studies were removed and full text of the articles was searched using Endnote software and manually. A total of 581 studies were identified from the literature search. Of these studies 13 articles of duplicate records were identified and removed. A total of 510 articles were excluded after reviewing the titles and 47 articles were excluded after reviewing abstracts because they were irrelevant. After assessing the full texts of the remaining 11 articles were left, 3 additional articles were excluded because of the following: poor quality, articles do not report outcome interest. Therefore, a total of 8 unique studies were eligible and enrolled for final analysis (Figure1).

The selected studies were(1), Abate et al,2020 from Addis Ababa(14),(2)Abdu et al.2020 from Eastern Ethiopia (15), (3)Legesse et al,2019, Aykel town, Ethiopia(16), (4)Wassie ET I,2014 Northwest Ethiopia (17), (5)Wondiye et al from Wolaita Sodo, Ethiopia (18),(6)Mezemir et al,2020 from Debre Birhan Ethiopia(19),(7)Z.K.Dhna et al,2019 from Debre Markos(20)and (8) Yisak et al,2021from South Gondar, zone Ethiopia,(21). The detailed description of selected studies is indicated in (Table2).

\section{Statistical analysis}

By dividing the number of positive subjects by the total number of study participants, the prevalence of undernutrition was estimated. The $\mathrm{I}^{2}$ test was used to examine the heterogeneity of the studies considered in this meta-analysis. The degree of diversity between each research is referred to as heterogeneity. Based on the $\mathrm{I}^{2}$ value less than $50 \%, 50$ - 75 percent, and above $>75$ percent, the studies' heterogeneity was characterized as low, moderate, and high, respectively. The studies included in the meta-analysis showed significant heterogeneity. As a result, the overall effect was estimated using a random-effect model with a $95 \%$ confidence interval. Stata software (version 14, STATA Corp College Station, TX) was used to conduct the meta-analysis, and p 0.05 was regarded statistically significant.

\section{Results}

\section{Prevalence of undernutrition among older adults}

In the estimation of the pooled prevalence of undernutrition, a total of 4,628 older adults from eight studies were included. $1^{2}$ test statistics were used to check the heterogeneity of the studies after a detailed examination by the authors. $I^{2}$ test statistics of $<50,50-75$, and $>75 \%$ were declared as low, moderate, 
and high heterogeneity respectively (22). Based on this, this study revealed that there was no variation across studies $\left(I^{2}=0.00 \%\right.$ and $\left.p<0.001\right)$. By using the fixed-effect model, the pooled prevalence of undernutrition among the older adults in Ethiopia was 20.53\% (95\% Cl: 17.39\%, 23.67\%) (Figur2).

\section{Associated factors of undemutrition among older adults}

All eight studies were included in the analysis of associated factors for undernutrition. Ten associated factors of undernutrition among older adults in Ethiopia were included in the analysis. The pooled odds ratio ranges from 0.15 to 13.07 . Heterogeneity was observed among studies for sex, age, and having depression. Sex, age, depression status, and wealth index were found to be statically significant factors of undernutrition among older adults whereas marital status, educational status, residence, dietary diversity score, meal frequency, and food intake status were not associated factors (Table 3).

The study revealed that males had higher odds of being undernutrition as compared to females with AOR 5.88 (95\% Cl: 5.00, 6.66). Older adults in the age range of 65-74 (young-old) were less likely to be undernutrition as compared to those whose age was above 85 (old-old) with AOR 022(0.22, 0.25). Older adults who were depressed had higher odds of undernutrition as compared to their counterparts with AOR 1.27 (1.19. 1.37). On the other hand, older adults from households with poor wealth index had two ( $A O R=1.90 ; 95 \% \mathrm{Cl} ; 1.08,3.32)$ times more likely to be undernutrition as compared to those who were from rich.

\section{Publication bias}

The presence of a small study effect was checked by using funnel plots and egger's test from the log-odds scale of the proportion for a better property of meta-analysis of a proportion. Standard Error (SE) is dependent on the value of log odds and the underlying proportion. Thus, a study in which $r(c a s e s)$ out of $n$ (sample size) patients were observed to have an event, gives a proportion of $r / n$. The associated log odds is $\ln (r /(n-r))$ with a $S E$ of sqrt $(1 / r+1 /(n-r))(23)$. Hence, the funnel plot showed asymmetric distribution and the egger's test was 0.967 , both results revealed that there was no publication bias (Figure 3 ).

\section{Discussion}

The pooled prevalence of undernutrition from a total of 4,628 older adults from eight studies among the older adults in Ethiopia is $20.53 \%$ (95\% Cl: $17.39 \%$, $23.67 \%$ ). This indicates that undernutrition is a significant public health problem among older adults. It was predicted that the prevalence of underweight in sub-Saharan Africa is expected to be up to (6-48\%) (24). A systematic c review in Africa found a lower pooled prevalence of undernutrition which was $19.9 \%$ which is comparable to the current study but the prevalence of the current study was lower than the Central African Republic (33.4\%) (25). Another study the Central African Republic (CAR) and the Republic of Congo (ROC)) reported that the prevalence of undernutrition was $19.2 \%$, which is comparable with the current result. It was $9.5 \%$ in ROC which is lower than the current result in Ethiopia. But it was (29.5\%) in CAR which is higher than the current result from Ethiopiathan that of CAR (26). A study from Nigeria found a lower prevalence (7.8\%)(27).

The results of this study found out that, older adults who were depressed had higher odds of undernutrition as compared to their counterparts with AOR 1.27 (1.19. 1.37). This is because depression leads to appetite and weight changes that result in undernutrition, and poor nutrition predisposes old individuals to psychiatric upset (depression, agitation, and irritability). A study from Brazil on undernutrition and depression among community-dwelling older adults People found that nutritional deficit presented a significant association with depression (OR $=4.38 ; 95 \% \mathrm{Cl}$ : $2.23-8.64 ; P<.001)(28)$. Similarly, a study from southern Brazil stated that depression was positively associated with the risk of undernutrition OR 2.4 ( $95 \% \mathrm{Cl} 0.79-7.38)(29)$. A population-based study on the association between undernutrition and depression in older adults People in Razavi Khorasan also concluded that there is a significant statistical difference between the prevalence of undernutrition in depressed and non-depressed individuals $(P=0.047)(30)$. Another study which was conducted in Bangladesh found out that being malnourished (OR: $4.05,95 \% \mathrm{Cl}$ : 2.79-5.87) and people are at risk of undernutrition (OR:1.67, 95\% Cl:1.24-2.24) had a significantly higher risk of suffering from depression. (31). Similarly, a multicenter, cross-sectional study from Turkey discovered that depression score (OR=95\% Cl: $1.104-$ $3.051 ; p=0.02$ ) was independently associated with undernutrition (32).

The current study revealed that males had higher odds of being undernutrition as compared to females with AOR 5.88 (95\% Cl: 5.00, 6.66). Due to their strong relation to fat-free mass, basal energy requirements are also influenced by gender and by nutritional status; REE/kg BW is higher for men than for women and increases with decreasing body mass index (BMI) (33).In contrast to the results of the current study, a study conducted in Italy aimed to asses Social and economic determinants of undernutrition found that a high prevalence of undernutrition was found out in both genders: $26 \%$ of females and $16.3 \%$ of males were classified as being malnourished (34). Similarly, a systematic review and meta-analysis of undernutrition and risk of undernutrition among the older adults ( $\geq 60$ years) in India reported that the prevalence of undernutrition was higher among females (16.67\%),(35). The multidimensional background of undernutrition among rural older individuals in Bangladesh investigated that, female gender $(P<0.05$ was independently associated with poor nutritional status(36). Another systematic review, meta-analysis, found a higher risk of undernutrition among females than males (odds ratio = 1.45 [95\% Cl: $1.27-1.66$ ]; $P<0.00001)(37)$.

The current study found that older adults from households with poor wealth index had two (AOR=1.90; $95 \% \mathrm{Cl} ; 1.08,3.32)$ times more likely to be undernutrition as compared to those who were from rich. This might be because rich individuals can invest more in purchasing food items as compared to the poor. By doing this the immediate cause of undernutrition (inadequate dietary intake) can be averted. In agreement with this, a systematic review and metaanalysis of observational studies on social and economic factors and undernutrition or the risk of undernutrition in the older adults indicated that low-income level (OR: 2.69; 95\% Cl: 2.35-3.08; p 0.001),(38). Another study on Social and economic correlates of undernutrition in the Polish older adult population indicated that self-reported poverty was an independent correlate of undernutrition(39). The assessment of the multidimensional background of undernutrition among rural older individuals in Bangladesh reported that, having no income $(P<0.01)$, being illiterate $(P<0.01)$, and not receiving regular financial support $(P$ $<0.05$ ) were also independently associated with poor nutritional status (36). 
Additionally, a cross-sectional survey in South Africa reported that a significantly higher percentage of participants from the lower socioeconomic area were found to be at risk of undernutrition than those from the higher socio-economic area (74.2\% vs. 37.1\%) [95\% $\mathrm{Cl} 19.8 \%$; $51.4 \%]$. Participants from the higher socio-economic area consumed significantly more fluid and protein-rich foods than their counterparts(40).

This study showed that older adults in the age range of 65-74 (young-old) were less likely to be undernutrition as compared to those whose age was above 85 (old-old) with AOR 022 $(0.22,0.25)$. It is supported by the fact that" The prevalence of undernutrition is increasing in this population and is associated with a decline in functional status, impaired muscle function, decreased bone mass, immune dysfunction, anemia, reduced cognitive function, poor wound healing, delayed recovery from surgery, higher hospital readmission rates, and mortality(41) ". Similarly, a report on Social and economic correlates of undernutrition in the Polish older adults population indicated that older age was an independent correlate of undernutrition(39). Moreover, a study on the Prevalence of Undernutrition among Institutionalized older adults people in Northern Peninsular Malaysia found that A significantly declined trend of anthropometric measurements was observed among the older adults between age groups 60-69 years and $\geq 80$ years (42).

\section{Conclusion}

The burden of undernutrition in Ethiopia is still significant, according to this report. As a result, different intervention measures to minimize the prevalence of undernutrition among Ethiopia's older adults are urgently needed. The current study finds some risk variables linked to undernutrition. The risk factors revealed in this study could be used by policymakers in the country to develop new intervention measures.

\section{Declarations}

\section{Ethical support}

Not applicable

\section{Accessibility of Data and Resources}

In the manuscript, all the data is available.

\section{Competing of Interests}

We, the authors, declare that there were no competing interests between us.

\section{Funding}

We didn't receive any funds for this review.

\section{Author Contributions}

All authors made a significant contribution to the work reported, whether that is in the conception, study design, execution, acquisition of data, analysis, and interpretation, or in all these areas; took part in drafting, revising, or critically reviewing the article; gave final approval of the version to be published; have agreed on the journal to which the article has been submitted; and agree to be accountable for all aspects of the work.

\section{References}

1. Capistrant BD, Glymour MM, Berkman LF. Assessing mobility difficulties for cross-national comparisons: results from the World Health Organization Study on Global AGEing and Adult Health. Journal of the American Geriatrics Society. 2014;62(2):329-35.

2. Rynning E. The aging populations of Europe-implications for health systems and patients' rights. European journal of the health law. 2008;15(3):297306.

3. Zohoori N. Nutrition and healthy functioning in the developing world. The Journal of nutrition. 2001;131(9):2429S-32S.

4. Fuster V. Changing demographics: a new approach to global health care due to the aging population. American College of Cardiology Foundation Washington, DC; 2017.

5. Agarwal E, Miller M, Yaxley A, Isenring E. Undernutrition in the older adults: a narrative review. Maturitas. 2013;76(4):296-302.

6. Milne AC, Potter J, Vivanti A, Avenell A. Protein and energy supplementation in older adults people at risk from undernutrition. Cochrane database of systematic reviews. 2009(2).

7. Chen $\mathrm{CCH}$, Schilling LS, Lyder CH. A concept analysis of undernutrition in older adults. Journal of advanced nursing. 2001;36(1):131-42.

8. Saka B, Kaya O, Ozturk GB, Erten N, Karan MA. Undernutrition in older adults and its relationship with other geriatric syndromes. Clinical nutrition. 2010;29(6):745-8.

9. Evans C. Undernutrition in the older adults: a multifactorial failure to thrive. The Permanente Journal. 2005;9(3):38. 
11. Hsiao PY, Mitchell D, Coffman D, Wood GC, Hartman T, Still C, et al. Dietary patterns and relationship to obesity-related health outcomes and mortality in adults 75 years of age or greater. The journal of nutrition, health \& aging. 2013;17(6):566-72.

12. Huang C, Wang Y, Li X, Ren L, Zhao J, Hu Y, et al. Clinical features of patients infected with 2019 novel coronavirus in Wuhan, China. The lancet. 2020;395(10223):497-506.

13. Cevallos M, Egger M, Moher D. STROBE (Strengthening the Reporting of Observational Studies in Epidemiology). Guidelines for reporting health research: a user's manual. 2014:169-79.

14. Abate T, Mengistu B, Atnafu A, Derso T. Undernutrition and its determinants among older adults people in Addis Ababa, Ethiopia. BMC geriatrics. 2020;20(1):1-9.

15. Abdu AO, Yimamu ID, Kahsay AA. Predictors of undernutrition among older adults aged above 65 years in eastern Ethiopia: neglected public health concern. BMC geriatrics. 2020;20(1):1-11.

16. Legesse M, Abebe Z, Woldie H. Chronic energy deficiency and associated factors among the older population in Ethiopia: A community-based study. PloS one. 2019;14(4):e0214861.

17. Tessfamichael D, Gete AA, Wassie MM. High prevalence of undernutrition among older adults people in Northwest Ethiopia: a cross-sectional study. Read Write. 2014;244:32.2.

18. Wondiye K, Asseffa NA, Gemebo TD, Astawesegn FH. Predictors of undernutrition among the older adults in Sodo zuriya district Wolaita zone, Ethiopia. BMC nutrition. 2019;5(1):1-7.

19. Mezemir Y, Egata G, Geset D, Lambebo A. Nutritional Status and Associated Factors Among the Community-Dwelling Older adults Population in Debre Berhan Town, North Shewa Zone, Ethiopia. Nutrition and Dietary Supplements. 2020;12:289-99.

20. Adhana Z, Tessema G, Getie G. PREVALENCE OF UNDER NUTRITION AND ASSOCIATED FACTORS AMONG PEOPLE OF OLD AGE IN DEBRE MARKOS TOWN, NORTHWEST ETHIOPIA, 2015.

21. Yisak H, Maru I, Abie M, Aragie G, Ewunetei A, Mamuye M, et al. Determinants of undernutrition among the older adults in South Gondar Zone, Ethiopia. Ethiopia (4/22/2021). 2021.

22. Higgins JP, Thompson SG, Deeks JJ, Altman DG. Measuring inconsistency in meta-analyses. Bmj. 2003;327(7414):557-60.

23. Hunter JP, Saratzis A, Sutton AJ, Boucher RH, Sayers RD, Bown MJ. In meta-analyses of proportion studies, funnel plots were found to be an inaccurate method of assessing publication bias. Journal of clinical epidemiology. 2014;67(8):897-903.

24. Kimokoti RW, Hamer DH. Nutrition, health, and aging in sub-Saharan Africa. Nutrition reviews. 2008;66(11):611-23.

25. Mabiama G, Adiogo D, Millimono T, Fayemendy P, Vernier T, Boumediene F, et al. Undernutrition, overweight and obesity among older adults living in communities in Africa: a systematic review. Proceedings of the Nutrition Society. 2021;80(OCE4).

26. Jésus $P$, Guerchet M, Pilleron S, Fayemendy P, Mouanga AM, Mbelesso P, et al. Undernutrition and obesity among older adults people living in two cities of developing countries: prevalence and associated factors in the EDAC study. Clinical Nutrition ESPEN. 2017;21:40-50.

27. Adebusoye L, Ajayi I, Dairo M, Ogunniyi A. Nutritional status of older persons presenting in a primary care clinic in Nigeria. Journal of nutrition in gerontology and geriatrics. 2012;31(1):71-85.

28. Cabrera MAS, Mesas AE, Garcia ARL, de Andrade SM. Undernutrition and depression among community-dwelling older adults people. Journal of the American Medical Directors Association. 2007;8(9):582-4.

29. DC LS. Association between undernutrition and depression in older adults. Nutrición hospitalaria. 2014;29(4):901-6.

30. Mokhber N, Majdi M, Ali-Abadi M, Shakeri M, Kimiagar M, Salek R, et al. association between undernutrition and depression in older adults people in Razavi Khorasan: a population-based study in Iran. Iranian journal of public health. 2011;40(2):67.

31. Alam MR, Karmokar S, Reza S, Kabir MR, Ghosh S, Al Mamun MA. Geriatric undernutrition and depression: Evidence from older adults home care population in Bangladesh. Preventive medicine reports. 2021;23:101478.

32. Gündüz E, Eskin F, Gündüz M, Bentli R, Zengin Y, Dursun R, et al. Undernutrition in community-dwelling older adults in Turkey: a multicenter, crosssectional study. Medical science monitor: international medical journal of experimental and clinical research. 2015;21:2750.

33. Gaillard C, Alix E, Salle A, Berrut G, Ritz P. Energy requirements in frail older adults people: a review of the literature. Clinical nutrition. 2007;26(1):16-24. 
34. Donini LM, Scardella P, Piombo L, Neri B, Asprino R, Proietti A, et al. Undernutrition in older adults: social and economic determinants. The journal of nutrition, health \& aging. 2013;17(1):9-15.

35. Kushwaha S, Kiran T, Srivastava R, Jain R, Khanna P, Singh T. Estimates of undernutrition and risk of undernutrition among the older adults ( $\geq 60$ years) in India: A systematic review and meta-analysis. Ageing Research Reviews. 2020:101137.

36. Ferdous T, Kabir ZN, Wahlin A, Streatfield K, Cederholm T. The multidimensional background of undernutrition among rural older individuals in Bangladesh-a challenge for the Millennium Development Goal. Public health nutrition. 2009;12(12):2270-8.

37. Crichton M, Craven D, Mackay H, Marx W, de van der Schueren M, Marshall S. A systematic review, meta-analysis and meta-regression of the prevalence of protein-energy undernutrition: associations with geographical region and sex. Age and aging. 2019;48(1):38-48.

38. Besora-Moreno M, Llauradó E, Tarro L, Solà R. Social and economic factors and undernutrition or the risk of undernutrition in the older adults: a systematic review and meta-analysis of observational studies. Nutrients. 2020;12(3):737.

39. Krzymińska-Siemaszko R, Mossakowska M, Skalska A, Klich-Rączka A, Tobis S, Szybalska A, et al. Social and economic correlates of undernutrition in Polish older adults population: the results of PolSenior study. The journal of nutrition, health \& aging. 2015;19(4):397-402.

40. Robb L, Walsh CM, Nel M, Nel A, Odendaal H, van Aardt R. Undernutrition in the older adults residing in long-term care facilities: a cross sectional survey using the Mini Nutritional Assessment (MNA®) screening tool. South African Journal of Clinical Nutrition. 2017;30(2).

41. Amarya S, Singh K, Sabharwal M. Changes during aging and their association with undernutrition. Journal of Clinical Gerontology and Geriatrics. 2015;6(3):78-84.

42. Chen ST, Ngoh HJ, Harith S. Prevalence of undernutrition among institutionalized older adults people in Northern Peninsular Malaysia: gender, ethnicity, and age-specific. Sains Malaysiana. 2012;41(1):141-8.

\section{Tables}

Table 1: Quality assessment of studies included in this study

\begin{tabular}{|c|c|c|c|c|c|c|c|c|c|}
\hline Studies & $\begin{array}{l}\text { Sample size } \\
\text { determination }\end{array}$ & $\begin{array}{l}\text { Sampling } \\
\text { methodology }\end{array}$ & $\begin{array}{l}\text { Statistical } \\
\text { methods }\end{array}$ & $\begin{array}{l}\text { Response } \\
\text { rate }\end{array}$ & $\begin{array}{l}\text { Outcome } \\
\text { measure }\end{array}$ & Confounding & $\begin{array}{l}\text { Study } \\
\text { limitation }\end{array}$ & $\begin{array}{l}\text { Ethical } \\
\text { consideration }\end{array}$ & $\begin{array}{l}\text { Overall } \\
\text { quality } \\
\text { assessment } \\
\text { score }\end{array}$ \\
\hline $\begin{array}{l}\text { Abate } 2020 \\
\text { et al. } \\
2020\end{array}$ & 1 & 1 & 1 & 1 & 1 & 1 & 1 & 1 & 8 \\
\hline $\begin{array}{l}\text { Abdu et } \\
\text { al.2020 }\end{array}$ & 1 & 1 & 1 & 0 & 1 & 1 & 1 & 1 & 7 \\
\hline $\begin{array}{l}\text { Legese et } \\
\text { al,2019 }\end{array}$ & 1 & 0 & 1 & 1 & 1 & 1 & 1 & 1 & 7 \\
\hline $\begin{array}{l}\text { Wassie et } \\
\text { al.2014 }\end{array}$ & 1 & 0 & 1 & 1 & 1 & 1 & 1 & 1 & 7 \\
\hline $\begin{array}{l}\text { Wondiye et } \\
\text { al019 }\end{array}$ & 1 & 1 & 1 & 1 & 1 & 1 & 1 & 1 & 8 \\
\hline $\begin{array}{l}\text { Mezimir et } \\
\text { al2020 }\end{array}$ & 0 & 1 & 1 & 1 & 1 & 1 & 0 & 1 & 6 \\
\hline $\begin{array}{l}\text { Z.K. dhana } \\
2019\end{array}$ & 1 & 1 & 1 & 1 & 1 & 1 & 1 & 1 & 8 \\
\hline $\begin{array}{l}\text { Hiwot Yisak } \\
\text { et al.2021 }\end{array}$ & 0 & 1 & 1 & 1 & 1 & 1 & 0 & 1 & 6 \\
\hline
\end{tabular}

Table 2: Summary of included studies to assess the prevalence and associated factors of undernutrition among older adults in Ethiopia,2021. 


\begin{tabular}{|c|c|c|c|c|c|c|c|c|}
\hline S.no & Author name & year & $\begin{array}{l}\text { Study } \\
\text { design }\end{array}$ & Region & $\begin{array}{l}\text { Sample } \\
\text { size }\end{array}$ & $\begin{array}{l}\text { Response rate } \\
(\%)\end{array}$ & $\begin{array}{l}\text { Prevalence } \\
\text { (\%) }\end{array}$ & $\begin{array}{l}\text { Quality } \\
\text { score }\end{array}$ \\
\hline 1 & Abate et al. & 2020 & CBCS & $\begin{array}{l}\text { Addis } \\
\text { Ababa }\end{array}$ & 682 & 97 & 26.6 & 8 \\
\hline 2 & Abdu et al. & 2020 & CBCS & Harari & 630 & 93.4 & 15.7 & 7 \\
\hline 3 & $\begin{array}{l}\text { Legesse M, Abebe Z, Woldie } \\
\mathrm{H}\end{array}$ & 2019 & CBCS & Amhara & 921 & 96.8 & 17.6 & 7 \\
\hline 4 & Wassie et al. & 2014 & CBCS & Amhara & 757 & 100 & 21.9 & 7 \\
\hline 5 & Wondiye et al & 2019 & CBCS & SNNP & 578 & 95.8 & 17.1 & 8 \\
\hline 6 & Mezmur et al & 2020 & CBCS & Amhara & 347 & 98.3 & 21.2 & 6 \\
\hline 7 & Z.K. Adhana & 2019 & CBCS & Amhara & 423 & 100 & 22.7 & 8 \\
\hline 8 & Hiwot Yisak et al. & 2021 & CBCS & Amhara & 300 & 96.6 & 27.6 & 6 \\
\hline
\end{tabular}

$\mathrm{CBCS}=$ community based crossectional study; SNNP= Southern Nations Nationalities and People

Table 3: Summary of meta-analysis for associated factors of undernutrition among older adults in Ethiopia, 2021.

\begin{tabular}{|c|c|c|c|c|c|c|c|}
\hline \multirow[t]{2}{*}{ S.no } & \multirow[t]{2}{*}{ Factors } & \multirow[t]{2}{*}{ No.of studies } & \multirow[t]{2}{*}{ OR(95\% CI) } & \multirow[t]{2}{*}{ P-value } & \multicolumn{3}{|c|}{ Heterogeneity } \\
\hline & & & & & Q-value & P-value & $\mathrm{I}^{2}(\%)$ \\
\hline 1 & Sex(female) & 5 & $0.17(0.15,0.20)$ & $<0.001$ & 116.35 & $<0.001$ & 96.6 \\
\hline \multirow[t]{3}{*}{2} & Age(oldold) & & & & & & \\
\hline & Youngold & 5 & $0.22(0.20,0.25)$ & $<0.001$ & 63.6 & $<0.001$ & 92.1 \\
\hline & Middleold & 4 & $1.63(0.78,3.40)$ & 0.195 & 0.78 & 0.855 & 0.0 \\
\hline 3 & Depression(yes) & 3 & $1.27(1.19,1.37)$ & $<0.001$ & 12.42 & 0.002 & 83.9 \\
\hline \multirow[t]{3}{*}{4} & Wealth index (rich) & & & & & & \\
\hline & poor & 5 & $1.90(1.08,3.32$ & 0.025 & 0.19 & 0.996 & 0.0 \\
\hline & middle & 5 & $1.13(0.77,1.66)$ & 0.517 & 3.54 & 0.316 & 15.3 \\
\hline 5 & Maritalstatus(not-married) & 3 & $1.79(0.82,3.90)$ & 0.143 & 0.43 & 0.807 & 0.0 \\
\hline 6 & Educational status(no education) & 4 & $2.00(0.98,4.05)$ & 0.055 & 0.20 & 0.977 & 0.0 \\
\hline 7 & Residence(rural) & 2 & $2.10(0.70,6.30)$ & 0.183 & 0.06 & 0.807 & 0.0 \\
\hline \multirow[t]{3}{*}{8} & DDS(good) & & & & & & \\
\hline & DDS(middle) & 2 & $1.16(0.79,1.69)$ & 0.446 & 0.06 & 0.804 & 0.0 \\
\hline & DDS(poor) & 2 & $4.28(0.43,13.07)$ & 0.217 & 0.03 & 0.871 & 0.0 \\
\hline 9 & Meal frequency $(<=2)$ & 2 & $1.46(0.82,2.56)$ & 0.196 & 0.34 & 0.559 & 0.0 \\
\hline 10 & Declined food intake(yes) & 2 & $2.17(0.44,10.66)$ & 0.338 & 0.10 & 0.757 & 0.0 \\
\hline
\end{tabular}

Youngold $=65-74$, middleold $=75-84$, oldold $=>=85, \mathrm{DDS}=$ dietary diversity score, $\mathrm{OR}=$ odds ratio,

$\mathrm{CI}=$ confidence interval, $\mathrm{Q}$-value= implies study variability, $\mathrm{I}^{2}$ (Tau-square) = estimated variance of the observed effect size

\section{Figures}




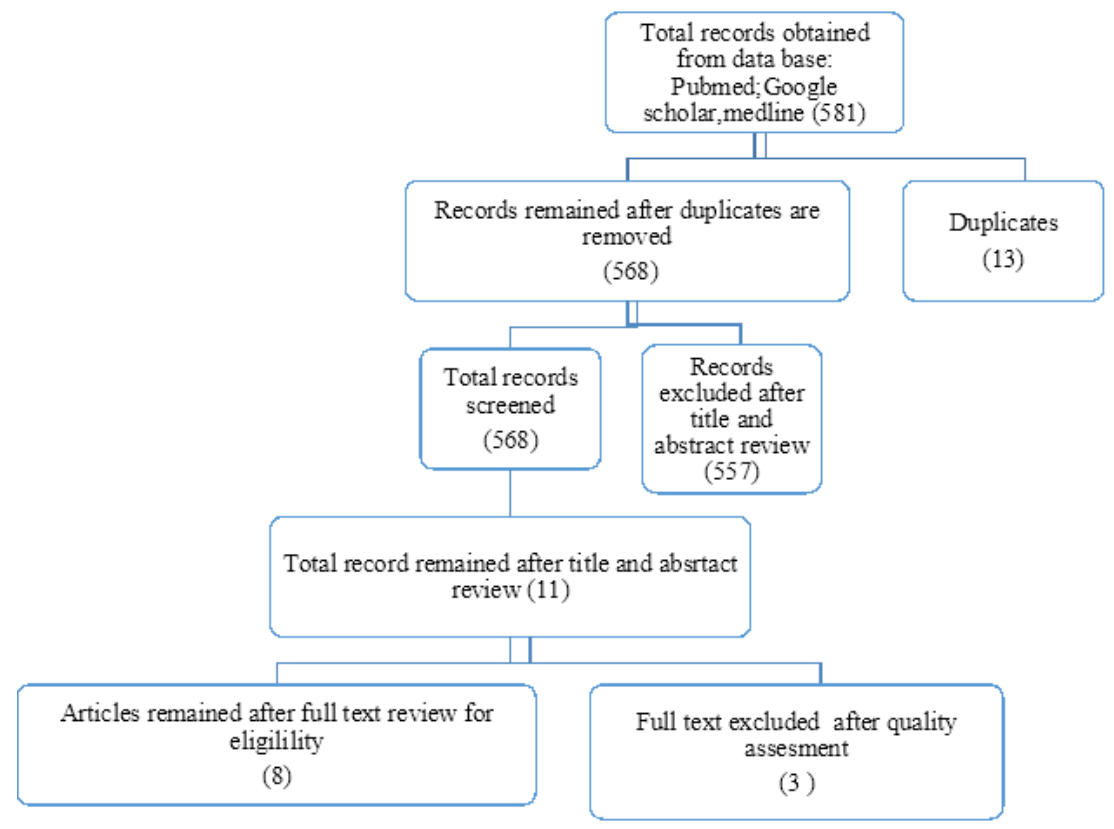

Figure 1

Flow diagram depicting the selection process for articles included in this review and meta-analysis

Study

Effect Size

Weight

with $95 \% \mathrm{Cl}$

(\%)

Wassie et al., 2014

Wondiye et al, 2019

Legesse M, Abebe Z, Woldie H, 2019

Z.K. Adhana, 2019

Mezmur et al, 2020

Abate et al., 2020

Abdu et al., 2020

Hiwot Yisak et al., 2021

\section{Overall}

Heterogeneity: $I^{2}=0.00 \%, H^{2}=0.88$

Test of $\theta_{i}=\theta_{j}: Q(7)=6.19, p=0.52$

Test of $\theta=0: z=12.83, p<0.001$

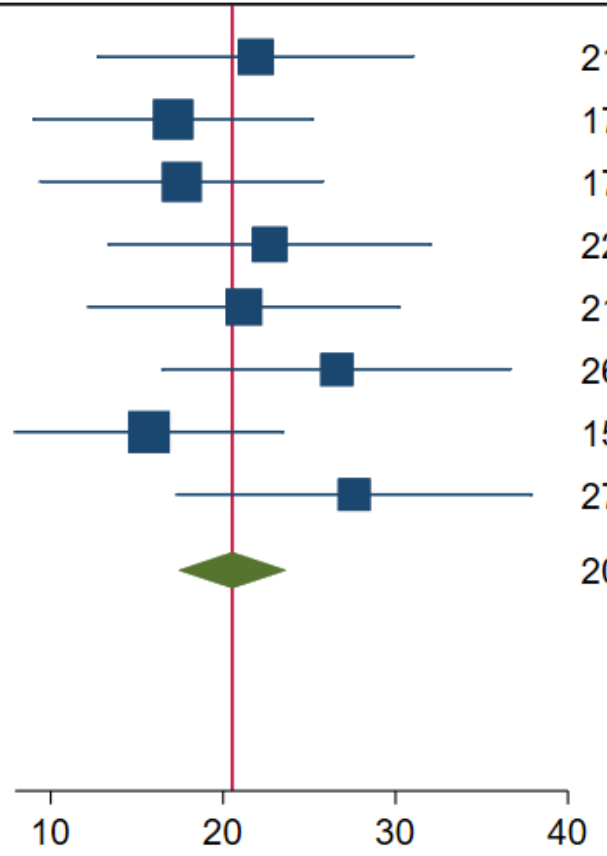

21.90 [ 12.73, 31.07] 11.71

$17.10[9.00,25.20] 15.00$

17.60 [ 9.38, 25.82] 14.57

22.70 [ 13.37, 32.03] 11.31

21.20 [ 12.19, 30.21] 12.12

26.60 [ 16.50, 36.70] 9.64

15.70 [ 7.94, 23.46] 16.34

27.60 [ 17.32, 37.88] 9.31

$20.53[17.39,23.67]$

\section{Fixed-effects inverse-variance model}

Figure 2

The pooled prevalence of undernutrition with its $95 \% \mathrm{Cl}$ among elders in Ethiopia, 2021 


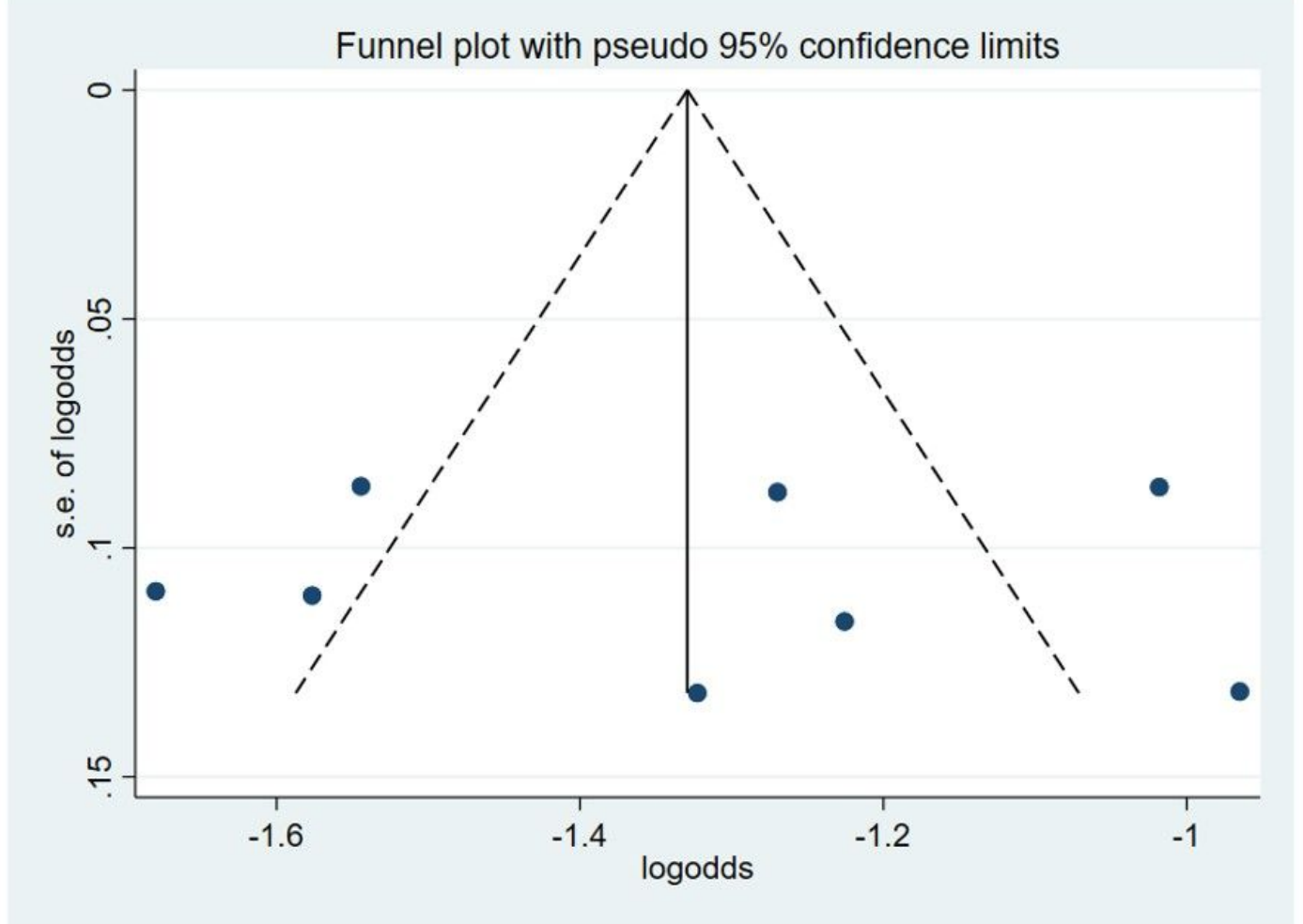

\section{Egger's test}

\begin{tabular}{lllllll}
\hline Std_Eff & Coef. & Std. Err. & $\mathrm{t}$ & $\mathrm{P}>\mathrm{t}$ & {$[95 \%$ Conf. } & Interval] \\
slope & -1.354529 & .5975185 & -2.27 & 0.064 & -2.816604 & .1075466 \\
bias & .2481365 & 5.790611 & 0.04 & 0.967 & -13.92098 & 14.41725 \\
\hline
\end{tabular}

Figure 3

funnel plot and eggers test to assess publication bias for undernutrition among elders in Ethiopia, 2021. 